\title{
Future of health system hinges on collaboration: outgoing CMA pres
}

- Cite as: CMAJ 2017 September 5;189:E1123-4. doi: 10.1503/cmaj.1095477

Posted on cmajnews.com on Aug. 16, 2017, updated on Aug. 23, 2017.

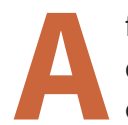

fter a divisive 12 months for Canada's health system and physicians, outgoing Canadian Medical Association (CMA) President Dr. Granger Avery is urging doctors, patients and governments to refocus on collaboration.

From the failure of governments to strike a health accord to repeated reports of bullying within health care, "it is now resoundingly clear that the health of the profession is at stake."

"We have underperforming systems. We have doctors who are increasingly anxious and working harder and harder to make our system work, but are not well supported," he says. However, "the very fact our system is under pressure actually helps us think about how we should be doing this together."
The "current attack" by the federal government to curtail tax benefits used by most doctors to offset the risks of self-employment "reflects the way we don't work well together," Avery says. But the most contentious debates over medical aid in dying, marijuana reform and seniors care also proved to be "profound" opportunities for physicians to mediate consensus.

The CMA will ramp up that role as part of a new three-year strategy that refocuses the organization on advocacy for patients and "collaborative dialogue." Avery says this shift toward a more outward-facing profession "really reflects why we became doctors in the first place."

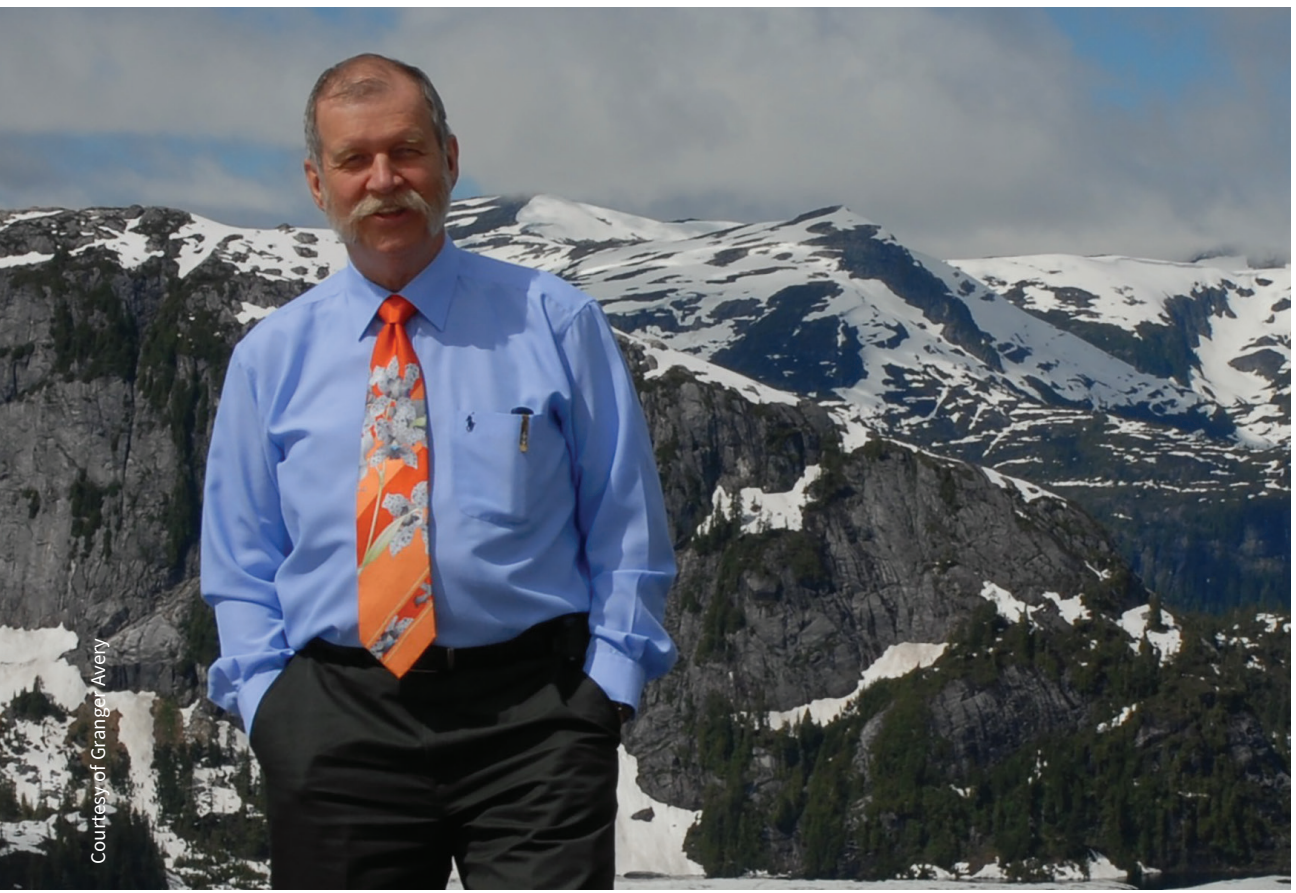

Outgoing Canadian Medical Association President Dr. Granger Avery says doctors can't afford to let system pressures divide them.

Now wrapping up his term as president, Avery spoke to CMAJ about why it's critical for the profession to pull together under mounting system pressures.

The health accord negotiations were one of your top concerns heading into your presidency. What are your reflections on how those discussions fell apart and where it leaves the health system now?

The government missed an opportunity to improve our health care system and it's not a surprise. We are in a system in Canada which is so very partite that it's really difficult to bring it together. ... We look at parts of the system because people fear looking at the whole system is a problem too big; it's like boiling the ocean. I don't believe that's true. ... We cannot afford for the country to continue to make decisions this way. It's expensive, we're underperforming and we're burning our people out doing it.

\section{You also set out to restore}

collegiality to the profession. At the time, there were already reports of bullying and intimidation in Ontario, and those have surfaced again recently. How are the profession and CMA addressing those issues?

The fact is the system is under stress and people respond in different ways when they're under stress - some people retire from the fray, others become more aggressive, and so on. In most cases, I don't fault individuals. ... Unless and until we make collaborative decisions, we are going to end up with factions and infighting. 
How is CMA strengthening those bonds of professionalism?

CMA has embarked on a review of the code of ethics, for example. CMA has several different approaches to the profession to see where they are and what they would like to do, and to hear the stories and the difficulties doctors face in their everyday lives. ... I've held meetings of doctors in Fredericton, Vancouver and Winnipeg looking at the stressors doctors are under and what needs to be done and those are remarkably similar. Too much work, too much demand, not enough time, constraints about the payment models, and indeed how much the payment is ... all issues that could be dealt with a collaborative approach.

There seems to be a shift towards a less collaborative approach on the part of government, given recent language used to present tax reforms that framed doctors as exploiting loopholes. How is their approach changing? I've been in medical politics for over 30 years ... and I was president of the British Columbia Medical Association when we had to aggressively take on the government, so no, I don't think it really has changed. When governments are stressed enough, they respond in a very bad way and I think we've seen that here. They've responded in a very shortsighted way. ... We need to sit down and talk about what it is we want on an equal footing, not in supplication. The idea of doctors asking government to please do this and that has passed; that's the 1950's approach.

\section{What's CMA's role in making that happen?}

We had over 50000 [members of the public] responding to our call for a seniors' strategy, so the ability of the CMA to connect with the people of Canada and the physicians of Canada is really strong. ... The government did fund two initiatives of the many that we were recommending at last budget, and the private members bill [calling for seniors' plan] has stimulated a committee response and tacit, if not overt, approval from the prime minister's office. Our advocacy and the rallying of people across the country had an effect and that has persuaded the federal government to do the right thing. ... It's a big step in the right direction.

\section{What's next after your term as president?}

I have a year of past-presidency where I think much of this can be continued and the concepts I want to pursue over the next while are simple. One, make our system work for patients and physicians through the collaborative approach. The second thing is paying close attention to physician health. That is fundamental; if we don't deal with that, we can't manage the other things. And the third thing is addressing practice models. It's not enough to talk about how you structure the system overall; we need to be thinking about how do you work on the ground, straddling that gulf between community practice and hospital practice, for example. ... That's going to be a lifetime's work, l'm sure.

Lauren Vogel, CMAJ 